\title{
Urinary Phthalate Levels Associated with the Risk of Nonalcoholic Fatty Liver Disease in Adults: The Korean National Environmental Health Survey (KoNEHS) 2012-2014
}

\author{
Yun-Jung Yang ${ }^{1}{ }^{1}$, Taehyen Kim $^{2}$ and Yeon-Pyo Hong ${ }^{3, *}$ \\ 1 Institute of Biomedical Science, Catholic Kwandong University International St. Mary's Hospital, \\ Incheon 22711, Korea; yangyj@ish.ac.kr \\ 2 College of Medicine, Catholic Kwandong University, Gangneung-si 25601, Korea; starkim3@naver.com \\ 3 Department of Preventive Medicine, College of Medicine, Chung-Ang University, Seoul 06974, Korea \\ * Correspondence: hyp026@cau.ac.kr; Tel.: +82-2-820-5667
}

check for updates

Citation: Yang, Y.-J.; Kim, T.; Hong, Y.-P. Urinary Phthalate Levels Associated with the Risk of Nonalcoholic Fatty Liver Disease in Adults: The Korean National Environmental Health Survey (KoNEHS) 2012-2014. Int. J. Environ. Res. Public Health 2021, 18, 6035. https://doi.org/10.3390/ ijerph18116035

Academic Editors:

Bruno Ramos-Molina and Fernando Cardona

Received: 23 February 2021

Accepted: 6 May 2021

Published: 4 June 2021

Publisher's Note: MDPI stays neutral with regard to jurisdictional claims in published maps and institutional affiliations.

Copyright: (c) 2021 by the authors. Licensee MDPI, Basel, Switzerland. This article is an open access article distributed under the terms and conditions of the Creative Commons Attribution (CC BY) license (https:// creativecommons.org/licenses/by/ $4.0 /)$.

\begin{abstract}
The prevalence of nonalcoholic fatty liver disease (NAFLD) is increasing worldwide. Recent experimental studies suggested that phthalates might induce NAFLD. Therefore, this study aimed to investigate the relationship between phthalates metabolites and NAFLD in the human population. This cross-sectional analysis was performed using data from the Korean National Environmental Health Survey II (2012-2014) among Korean adults $(n=5800)$. NAFLD was diagnosed using the hepatic steatosis index (HSI) in the absence of other causes of chronic liver diseases. Among the participants (mean age 46 years, $47.5 \%$ male), the prevalence of NAFLD was associated with urinary levels of mono(2-ethyl-5-hydroxyhexyl) phthalate (MEHHP), mono-(2-ethyl-5-oxohexyl) phthalate, mono-(2-ethyl-5-carboxypentyl) phthalate, mono-benzyl phthalate (MBzP), and mono$n$-butyl phthalate (MnBP) compared to the reference group. In the multivariate model, the odds ratios (ORs), 95\% confidence interval (CI) for NAFLD were 1.33 (1.00-1.78) and 1.39 (1.00-1.92) in the 3rd and 4th quartile of MEHHP, respectively. Based on the study findings, high levels of urinary phthalates are associated with the prevalence of NAFLD in Korean adults. Further investigation is required to elucidate the causal relationship.
\end{abstract}

Keywords: phthalates; hepatic steatosis index; nonalcoholic fatty liver disease; Korean National Environmental Health Survey

\section{Introduction}

Nonalcoholic fatty liver disease (NAFLD) is a condition whereby there is a significant accumulation of fat in the liver ( $>5 \%$ fat content), without excessive consumption of alcohol or other causes of liver disease [1]. The global prevalence of NAFLD is estimated to be approximately $30 \%$, and it is likely to increase [1-3]. The presence of metabolic disorders, including obesity, type 2 diabetes, dyslipidemia, and hypertension, is considered to be a risk factor for NAFLD $[4,5]$.

While a Westernized diet and sedentary lifestyle may contribute the rapid increase of the NAFLD occurrence [2,6], recent studies suggests that exposure to endocrine disrupting chemicals (EDCs) may also associated with the pathogenesis of NAFLD through insulin resistance (IR) [7-9]. Although IR is one of the hallmarks of NAFLD progression, EDCs can directly affect hepatic lipid homeostasis $[10,11]$ because most of EDCs are metabolized in the liver, which is a central organ in energy metabolism.

Among the various EDCs, phthalates are the most commonly used plasticizers in industries and in daily life. Phthalates are a group of phthalic acid esters that are widely used to increase the flexibility in various consumer products including medical devices, children's toys, personal care products, and food wrap made of polyvinyl chloride (PVC). This widespread usage of phthalate has also led to a marked increase in the exposure of 
the public to these agents [12]. Phthalates entering the body are rapidly hydrolyzed to the monoesters in the liver and gut [13-15], and most of them are excreted through the urine and feces $[16,17]$. Previous studies have focused on the development and reproductive toxicity after phthalate exposure $[18,19]$. Recent studies have suggested that phthalates can induce obesity, insulin resistance, and metabolic disorders [20-25].

The occurrence of metabolic diseases after phthalate exposure might be linked to the activation of peroxisome proliferator-activated receptors (PPARs) [25,26], which are modulated by the sterol regulatory element binding proteins (SREBPs) [27]. In experimental studies, the disruption of gene expression related to fatty acid metabolism was suggested as a plausible mechanism in the development of NAFLD after phthalate exposure [28-34]. However, there is a lack of clinical evidence to support the phthalates-NAFLD relationships.

Therefore, this study aimed to investigate whether urinary phthalate metabolites are associated with the development of NAFLD in the population.

\section{Materials and Methods}

\subsection{Study Design and Participants}

This study was based on cross-sectional data obtained from the Korean National Environmental Health Survey (KoNEHS) II (2012-2014). KoNEHS is conducted every 3 years, and this is to measure the human exposure level of environmental chemicals, examine influential factors, and continuously investigate the factors of spatiotemporal distribution and changes [31]. It is a data set that includes national, multistage, stratified, and clustered probability sampling designs, so as to develop representative samples of the South Korean population.

The 6478 subjects in the KoNEHS II were aged 19 years and older (2274 men and 3704 women). They were interviewed with questionnaires on demographic characteristics, socioeconomic status, indoor/outdoor environment, lifestyle factors, and history of disease experience. Biological samples (urine and blood) were collected for clinical analysis and to measure the level of environmental chemicals. The published data of questionnaire, clinical tests, and urinary phthalate metabolite levels were used in this study.

Based on the data, 678 participants were excluded due to a lack of data of phthalate metabolites concentrations $(n=247)$, no data of alanine aminotransferase (ALT) or aspartate aminotransferase (AST) levels $(n=21)$, significant alcohol consumption $(n=262$, including males who consumed alcohol more than 3 times per week and 7-9 cups per time $(n=238)$ and females who consumed alcohol more than 3 times per week and 5-6 cups per time $(n=24))$, pregnant women $(n=29)$, those with hepatitis or hepatic disease $(n=59)$, and those with an AST/ALT ratio exceeding $2(n=60)$. Finally, 5800 participants ( 2355 men and 3445 women) were included in this analysis (Figure 1).

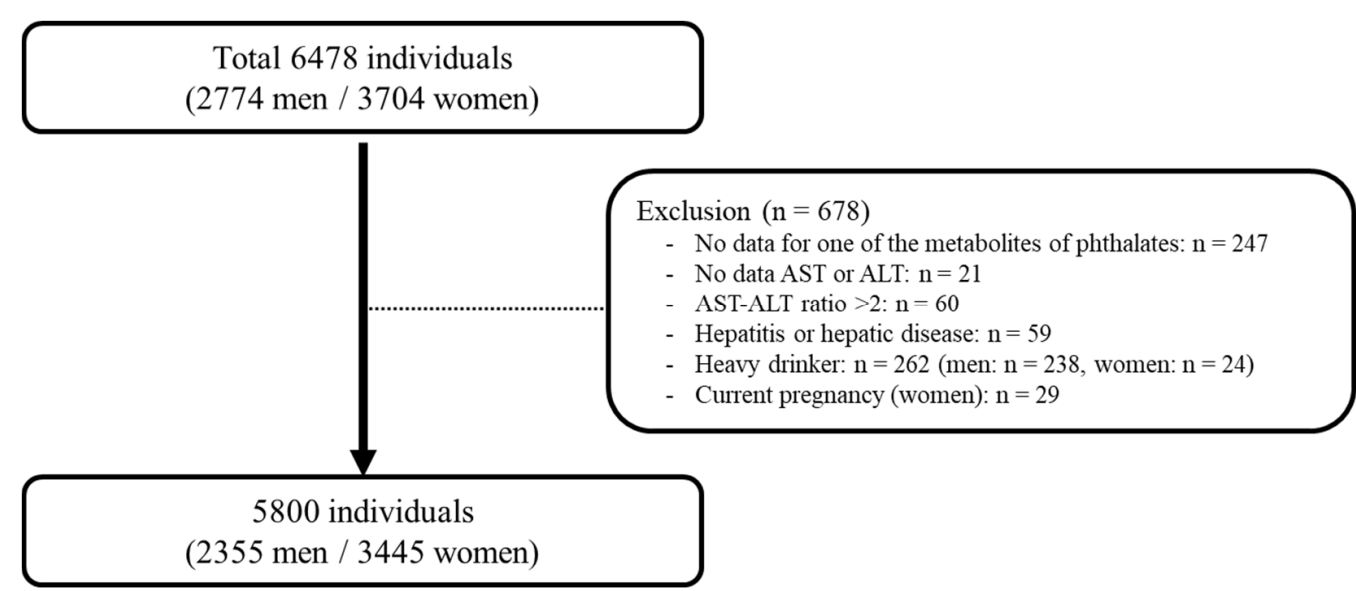

Figure 1. Study population in the present study obtained from the Korean National Environmental Health Survey II (2012-2014). AST: aspartate aminotransferase; ALT: alanine aminotransferase. 


\subsection{Questionnaires and Anthropometric Parameters}

Data on the participants' general characteristics, including age, sex, drinking and smoking status, physical activity, socioeconomic status, and education level, were obtained via interviews using questionnaires. These characteristics were categorized based on their responses as follows: education (less than high school, high school, and college and more), drinking and smoking (never, past, present), physical activity levels (no, moderate, yes), socioeconomic status (high, mid-high, mid-low, low), and marital status (single, married, and divorced/separated).

Participants who were diagnosed with hepatitis or fatty liver disease and who were currently undergoing treatment or taking medication were considered to have hepatic disease. Hypertension was defined as a self-reported history of hypertension or the use of antihypertensive drugs. Diabetes mellitus (DM) was defined as a self-reported history of $\mathrm{DM}$ or the use of antidiabetic drugs. Hyperlipidemia was defined as a self-reported history of hyperlipidemia, use of anti-hyperlipidemia drugs, triglyceride (TG) $\geq 240 \mathrm{mg} / \mathrm{dL}$, or high-density lipoprotein cholesterol $\leq 40 \mathrm{mg} / \mathrm{dL}$. Data on serum TG, ALT, and AST levels were obtained. Body mass index (BMI) was calculated by dividing body weight $(\mathrm{kg})$ by height squared $\left(\mathrm{m}^{2}\right)$.

\subsection{Definition of NAFLD}

The hepatic steatosis index (HSI) was used as a screening tool for NAFLD [35-37]. The variables in the HSI formula were levels of ALT, AST, BMI, sex, and presence of DM. Subjects were categorized into two groups based on the HSI score: $\leq 36$ was defined as non-NAFLD and $>36$ was defined as NAFLD.

$$
\mathrm{HSI}=8 \times \frac{\mathrm{ALT}}{\mathrm{AST}} \text { ratio }+ \text { BMI }(+2, \text { if diabetes } ;+2, \text { if female })
$$

\subsection{Statistical Analysis}

The weighted mean or frequency and standard errors were provided. Comparisons between groups were performed using the t-test (continuous variable) or $\chi^{2}$ test (categorical variables). The concentrations of phthalate metabolites were categorized into quartiles based on the weighted sample distribution. The lowest quartile group was considered as the reference. Because the levels of phthalate metabolites were skewed to the right, $\log$ transformation was required. Multivariate logistic regression analysis was performed to predict the relationship between phthalate levels and NAFLD after considering potential demographic and clinical variables. The included demographic covariates were age, sex, smoking, drinking, exercise level, marital status, education level, and socioeconomic status. Hypertension, DM, and hyperlipidemia were included as clinical variables. In logistic regression, BMI was not used as an independent variable. The reason for this decision was that BMI is used as part of the HSI calculation formula and to avoid collinearity between BMI and HSI. However, in the HSI formula, women's +2 is intended to compensate for women's lower BMI compared to men. For DM, +2 was used for the same reason, so in logistic regression, sex and DM were used as independent variables. Data analyses were performed using STATA (version 15.0 StataCorp LP College Station, TX, USA). $p$-values $<0.05$ were considered significant.

\section{Results}

\subsection{General Characteristics}

The participants were categorized according to their HSI score (Table 1), with 4405 and 1395 in the non-NAFLD and NAFLD groups, respectively. The proportion of gender was not statistically different between the non-NALFD and NAFLD groups $(p=0.061)$. The mean age and BMI were significantly higher in the NAFLD group than in the nonNAFLD group ( $p=0.005$ and $p<0.001$, respectively). The statuses of alcohol consumption were not significantly different between the two groups $(p=0.054)$; however, the status of smoking and regular exercise were significantly different (both $p=0.013$ ). Socioeconomic 
status, education level, and marital status also showed significant differences ( $p=0.040$, $p<0.001$, and $p<0.001$, respectively). The proportions of participants with hypertension, $\mathrm{DM}$, and hyperlipidemia were significantly higher in the NAFLD group than in the nonNAFLD group (all $p<0.001)$.

Table 1. General characteristics of study participants according to the hepatic steatosis index score.

\begin{tabular}{|c|c|c|c|}
\hline Variables & $\begin{array}{l}\text { Non-NAFLD } \\
(n=4405)\end{array}$ & $\begin{array}{l}\text { NAFLD } \\
(n=1395)\end{array}$ & $p$-Value \\
\hline Age (years) & $45.79 \pm 0.41$ & $47.70 \pm 0.62$ & 0.005 \\
\hline Gender (\%, men) & $46.68 \pm 0.79$ & $50.50 \pm 1.75$ & 0.061 \\
\hline BMI $\left(\mathrm{kg} / \mathrm{m}^{2}\right)$ & $22.81 \pm 0.05$ & $28.20 \pm 0.10$ & $<0.001$ \\
\hline Drinking Status (\%) & & & 0.054 \\
\hline Never & $29.90 \pm 0.91$ & $34.01 \pm 1.69$ & \\
\hline Former & $4.97 \pm 0.40$ & $3.98 \pm 0.62$ & \\
\hline Current & $65.12 \pm 1.00$ & $61.99 \pm 1.79$ & \\
\hline Smoking Status (\%) & & & 0.013 \\
\hline Never & $65.75 \pm 0.89$ & $61.59 \pm 1.78$ & \\
\hline Former & $15.23 \pm 0.65$ & $14.29 \pm 1.26$ & \\
\hline Current & $19.00 \pm 0.80$ & $24.10 \pm 1.69$ & \\
\hline Physical activity (\%) & & & 0.013 \\
\hline No & $61.43 \pm 0.12$ & $66.64 \pm 1.76$ & \\
\hline Moderate & $22.06 \pm 1.03$ & $19.36 \pm 1.49$ & \\
\hline Vigorous & $16.50 \pm 0.82$ & $13.99 \pm 1.15$ & \\
\hline Socioeconomic status (\%) & & & 0.040 \\
\hline Low & $0.83 \pm 0.20$ & $1.09 \pm 0.39$ & \\
\hline Low-mid & $29.17 \pm 1.32$ & $26.92 \pm 2.00$ & \\
\hline Mid-high & $47.97 \pm 1.22$ & $45.01 \pm 1.95$ & \\
\hline High & $22.02 \pm 1.04$ & $26.96 \pm 1.91$ & \\
\hline Education (\%) & & & $<0.001$ \\
\hline$<$ High school & $22.99 \pm 0.98$ & $28.42 \pm 1.67$ & \\
\hline High school & $38.49 \pm 1.08$ & $38.80 \pm 1.83$ & \\
\hline College and more & $38.51 \pm 1.23$ & $32.76 \pm 1.93$ & \\
\hline Marital status (\%) & & & $<0.001$ \\
\hline Single & $19.67 \pm 1.05$ & $14.41 \pm 1.51$ & \\
\hline Married & $72.83 \pm 1.10$ & $74.93 \pm 1.75$ & \\
\hline Divorced & $7.48 \pm 0.52$ & $1.06 \pm 1.21$ & \\
\hline \multicolumn{4}{|l|}{ Comorbidity (\%) } \\
\hline Hypertension & $12.67 \pm 0.63$ & $24.38 \pm 1.54$ & $<0.001$ \\
\hline Diabetes mellitus & $3.82 \pm 0.33$ & $15.32 \pm 1.19$ & $<0.001$ \\
\hline Hyperlipidemia & $25.01 \pm 0.90$ & $48.99 \pm 1.79$ & $<0.001$ \\
\hline
\end{tabular}

Data are shown as the weighted mean or frequency \pm standard error as appropriate. NAFLD: non-alcoholic fatty liver disease; BMI: Body mass index.

\subsection{Urinary Levels of Phthalate Metabolites}

The distribution of urinary phthalate metabolites in the participants is shown in Table 2. Unadjusted urinary mono-(2-ethyl-5-hydroxyhexyl) phthalate (MEHHP) and mono-(2-ethyl-5-carboxypentyl) phthalate (MECPP) levels in the NAFLD group was significantly higher than those in the non-NAFLD group (both $p<0.001$ ). The urinary levels of mono-(2-ethyl-5-oxohexyl) phthalate (MEOHP) was significantly higher in the NAFLD group compared to the non-NAFLD group $(p=0.031)$. Mono- $n$-butyl phthalate (MnBP), and mono-benzyl phthalate $(\mathrm{MBzP})$ in urine did not differ between the groups $(p=1.000$ and $p=0.085$, respectively). 
Table 2. Urinary phthalates levels according to hepatic steatosis index score.

\begin{tabular}{ccccc}
\hline $\begin{array}{c}\text { Concentrations } \\
(\mathbf{u g} / \mathrm{L}, \mathrm{GM} \pm \text { GSE) }\end{array}$ & $\begin{array}{c}\text { Total } \\
(\boldsymbol{n}=\mathbf{5 8 0 0})\end{array}$ & $\begin{array}{c}\text { Non-NAFLD } \\
(\boldsymbol{n}=\mathbf{4 4 0 5 )}\end{array}$ & $\begin{array}{c}\text { NAFLD } \\
(\boldsymbol{n}=\mathbf{1 3 9 5})\end{array}$ & $\boldsymbol{p}$-Value \\
\hline MEHHP & $2.922 \pm 0.011$ & $2.898 \pm 0.013$ & $3.000 \pm 0.023$ & $<0.001$ \\
MEOHP & $2.571 \pm 0.011$ & $2.558 \pm 0.013$ & $2.612 \pm 0.023$ & 0.031 \\
MECPP & $3.059 \pm 0.010$ & $3.039 \pm 0.012$ & $3.120 \pm 0.021$ & $<0.001$ \\
MnBP & $3.211 \pm 0.012$ & $3.212 \pm 0.014$ & $3.208 \pm 0.024$ & 1.000 \\
MBzP & $1.047 \pm 0.015$ & $1.033 \pm 0.017$ & $1.091 \pm 0.031$ & 0.085 \\
\hline
\end{tabular}

GE: geometric mean; GSE: geometric standard error; NAFLD: non-alcoholic fatty liver disease; MEHHP: mono (2-ehtyl-5-hydroxyhexyl) phthalate; MEOHP: mono (2-ethyl-5-oxohexyl) phthalate; MECPP: mono (2-ethyl-5carboxypentyl) phthalate; MnBP: mono- $n$-butyl phthalate; MBzP: mono-benzyl phthalate.

\subsection{The Association between Urinary Phthalate Metabolites and HSI Score}

The multivariate odds ratios (ORs) and $95 \%$ confidence intervals (CIs) for the HSI score according to urinary phthalate levels are shown in Table 3. The lowest level of each phthalate (first quartile) was considered as the reference value.

Table 3. The association between hepatic steatosis index score and urinary phthalates levels (ug/L).

\begin{tabular}{|c|c|c|c|c|c|c|c|c|}
\hline \multirow{2}{*}{$\begin{array}{l}\text { Phthalate } \\
\text { Metabolites }\end{array}$} & \multicolumn{2}{|c|}{ Crude } & \multicolumn{2}{|c|}{ Model 1} & \multicolumn{2}{|c|}{ Model 2} & \multicolumn{2}{|c|}{ Model 3} \\
\hline & OR $(95 \% \mathrm{CI})$ & $p$-Value & OR $(95 \%$ CI $)$ & $p$-Value & OR $(95 \%$ CI) & $p$-Value & OR $(95 \% \mathrm{CI})$ & $p$-Value \\
\hline \multicolumn{9}{|l|}{ MEHHP } \\
\hline Quartile 1 & 1 & $<0.001 *$ & 1 & $0.008 *$ & 1 & $0.015^{*}$ & 1 & 0.019 * \\
\hline Quartile 2 & $1.09(0.85-1.40)$ & 0.482 & $1.09(0.83-1.44)$ & 0.514 & $1.07(0.81-1.42)$ & 0.594 & $1.05(0.80-1.38)$ & 0.702 \\
\hline Quartile 3 & $1.39(1.14-1.71)$ & 0.001 & $1.40(1.08-1.81)$ & 0.010 & $1.34(1.02-1.76)$ & 0.030 & $1.33(1.00-1.78)$ & 0.044 \\
\hline Quartile 4 & $1.41(1.12-1.77)$ & 0.003 & $1.43(1.04-1.95)$ & 0.024 & $1.40(1.02-1.93)$ & 0.035 & $1.39(1.00-1.92)$ & 0.044 \\
\hline \multicolumn{9}{|l|}{ MEOHP } \\
\hline Quartile 1 & 1 & $0.069 *$ & 1 & 0.657 * & 1 & 0.784 * & 1 & 0.835 * \\
\hline Quartile 2 & $1.10(0.86-1.40)$ & 0.445 & $1.04(0.80-1.35)$ & 0.751 & $1.03(0.79-1.34)$ & 0.784 & $1.01(0.77-1.31)$ & 0.929 \\
\hline Quartile 3 & $1.12(0.98-1.51)$ & 0.067 & $1.10(0.83-1.46)$ & 0.480 & $1.07(0.80-1.44)$ & 0.618 & $1.05(0.77-1.43)$ & 0.732 \\
\hline Quartile 4 & $1.19(0.96-1.49)$ & 0.109 & $1.05(0.78-1.42)$ & 0.723 & $1.03(0.76-1.40)$ & 0.827 & $1.02(0.74-1.39)$ & 0.888 \\
\hline \multicolumn{9}{|l|}{ MECPP } \\
\hline Quartile 1 & 1 & 0.020 * & 1 & $0.214^{*}$ & 1 & $0.267^{*}$ & 1 & 0.245 * \\
\hline Quartile 2 & 1.07 (0.85-1.36) & 0.531 & $1.04(0.80-1.35)$ & 0.729 & $1.03(0.80-1.34)$ & 0.773 & $1.01(0.77-1.31)$ & 0.935 \\
\hline Quartile 3 & $1.28(1.04-1.59)$ & 0.020 & $1.20(0.91-1.58)$ & 0.179 & $1.17(0.88-1.55)$ & 0.270 & $1.14(0.85-1.54)$ & 0.365 \\
\hline Quartile 4 & $1.26(1.00-1.60)$ & 0.047 & $1.18(0.86-1.62)$ & 0.287 & $1.17(0.84-1.61)$ & 0.337 & $1.18(0.85-1.65)$ & 0.311 \\
\hline \multicolumn{9}{|l|}{$\mathrm{MBzP}$} \\
\hline Quartile 1 & 1 & 0.533 * & 1 & 0.664 * & 1 & 0.710 * & 1 & $0.792 *$ \\
\hline Quartile 2 & $1.08(0.86-1.37)$ & 0.467 & $1.02(0.80-1.30)$ & 0.853 & $1.07(0.84-1.36)$ & 0.573 & $1.05(0.82-1.34)$ & 0.673 \\
\hline Quartile 3 & $1.14(0.92-1.42)$ & 0.220 & $1.03(0.80-1.32)$ & 0.711 & $1.08(0.84-1.38)$ & 0.529 & $1.06(0.82-1.35)$ & 0.641 \\
\hline Quartile 4 & $1.06(0.84-1.34)$ & 0.612 & $0.93(0.70-1.23)$ & 0.626 & $0.94(0.71-1.24)$ & 0.678 & $0.95(0.72-1.26)$ & 0.769 \\
\hline \multicolumn{9}{|l|}{$\mathrm{MnBP}$} \\
\hline Quartile 1 & 1 & $0.860 *$ & 1 & 0.191 * & 1 & 0.304 * & 1 & 0.420 * \\
\hline Quartile 2 & $1.17(0.95-1.44)$ & 0.139 & $1.05(0.83-1.34)$ & 0.630 & $1.08(0.85-1.38)$ & 0.492 & 1.07 (0.83-1.37) & 0.571 \\
\hline Quartile 3 & $1.08(0.86-1.34)$ & 0.481 & $0.90(0.68-1.18)$ & 0.449 & $0.93(0.71-1.22)$ & 0.632 & $0.94(0.72-1.23)$ & 0.685 \\
\hline Quartile 4 & $1.05(0.82-1.33)$ & 0.686 & $0.83(0.60-1.15)$ & 0.279 & $0.87(0.63-1.21)$ & 0.424 & $0.90(0.64-1.25)$ & 0.540 \\
\hline
\end{tabular}

OR: odds ratio; CI: confidence interval; MEHHP: mono (2-ehtyl-5-hydroxyhexyl) phthalate; MEOHP: mono (2-ethyl-5-oxohexyl) phthalate; MECPP: mono (2-ethyl-5-carboxypentyl) phthalate; MnBP: mono- $n$-butyl phthalate; MBzP: mono-benzyl phthalate. *: $p$ values were shown the test of trend of odds. Crude: hepatic steatosis index, each type of phthalate metabolites. Model 1: Crude + age, sex, creatinine. Model 2: Model 1 + smoking, drinking, exercise, marital status, education, socioeconomic status. Model 3: Model 2 + hypertension, diabetes mellitus, hyperlipidemia.

Urinary MEHHP and MECPP in 3rd and 4th quartiles showed higher ORs than those in the lowest quartile, in crude analysis. After adjusting for age, sex, and creatinine level (Model 1), adjusted ORs (95\% CI) of MEHHP in 3rd and 4th quartiles were 1.40 (1.08-1.81) and 1.43 (1.04-1.95), compared with those in the lowest quartile.

Additionally, adjusting for smoking status, drinking status, regular exercise, marital status, education level, and socioeconomic status was performed (Model 2). The adjusted ORs of MEHHP in the 3rd and 4th quartiles were significantly higher than those in the lowest quartile (1.34 [95\% CI 1.02-1.76] and 1.40 [95\% CI 1.02-1.93], respectively). 
When further adjusted for hypertension, DM, hyperlipidemia, and urinary bisphenol A levels (Model 3), adjusted ORs (95\% CI) were 1.33 (1.00-1.77) and 1.39 (1.00-1.92) in the 3 rd and 4th quartile of MEHHP, compared with those in the lowest quartile.

\section{Discussion}

This study was performed to investigate the association between urinary levels of phthalate metabolites and NAFLD in the population. The prevalence of NAFLD based on the HSI score was associated with higher levels of urinary MEHHP and MECPP in univariate analyses. After we adjusted the covariates, the 3rd and 4th quartiles of MEHHP showed significantly higher ORs compared to the lowest levels. The risk of developing NAFLD significantly increased as the quartiles of MEHHP increased in univariate and multivariate analyses.

Humans can be exposed to phthalates through ingestion (e.g., phthalate-contaminated food and water), dermal absorption (e.g., cosmetics and other personal care products), and inhalation (e.g., nail polish, hair spray, and other phthalate-containing products) [12]. Phthalates entering the body are rapidly hydrolyzed to monoesters and then metabolized in the liver and the gut [13-15] and excreted through the urine, with half-lives of less than 24 hours $[16,17]$. Phthalate monoesters represent the major human metabolites; however, the monoester of di-(2-ethylhexyl) phthalate (DEHP) is further metabolized and produced the secondary oxidized metabolites $[14,16,17]$. Thus, urine samples are commonly used to measure phthalate exposure.

Phthalates were classified as obesogen based on the previous animal studies on obesity and metabolic derangement $[25,38,39]$. Although NAFLD is closely associated with obesity [4], it also occurs in non-obese people [40,41]. That is, excess accumulation of visceral fats, which is related to IR, play a key role in NAFLD pathogenesis [41,42]. In cross-sectional studies, urinary phthalate metabolites showed an association with BMI, waist circumstances, and IR [20,21,23]. In addition, urinary MEHHP levels, which is the secondary oxidized metabolite of DEHP, showed a positive association with obesity and IR in prepubertal girls, but not with that of MEOHP and MECPP [43]. In human liver cell line, DEHP reduced insulin receptor levels and glucose oxidation, and subsequently increased IR [44]. Also, DEHP treated male rats experienced reduced insulin levels in serum and liver glycogen, and increased thyroid hormone levels in serum [22]. Because obesity and IR can contribute to the development of NAFLD [7-9], we hypothesized that phthalates could increase the risk of developing liver disease.

In experimental studies, exposure to DEHP, the most widely used phthalate, along with high fat or oleic acid in diets increased lipid content and inflammation in rat liver [28,33] and in a hepatocellular carcinoma cell line (HepG2 cells) [29]. The increase in hepatic lipid accumulation after phthalate exposure might be due to the up-regulation of genes related to hepatic lipid metabolism such as SREBPs and PPARs $[28,29,33]$. In transcriptome analysis, supporting evidence was identified for the association between exposure to a low dose of DEHP and the disruption of genes related to hepatic fatty acid metabolism in the zebrafish [30]. In addition, mono-2-ethylhexyl phthalate (MEHP), which is the primary metabolite of DEHP, increased the TG content and modulated the gene related to fatty acid metabolism in HepG2 cells [32]. In particular, perinatal exposure to DEHP induced hepatic TG content in adult male pups through up-regulation of diacylglycerol acyltransferase 1, regardless of obesity [34]. This study indicated that DEHP alone could influence re-esterification and increase small lipid droplets in the liver instead of activation of de novo lipogenesis. Although the experimental studies suggested that phthalates could accelerate lipogenesis and thereby contribute to the development of NAFLD, further study is needed to clarify the relationship between DEHP and NAFLD pathogenesis.

In addition, because thyroid hormones are important to regulate the glucose and lipid metabolism [45], the alteration of thyroid hormone levels due to phthalates may increase the risk of NAFLD. Previously, DEHP treated rats showed the decrease of thyroid hormones, sodium iodide symporter, and thyroid peroxidase levels [22,46]. It seems that DEHP can 
disrupt the thyroid hormone synthesis, transport, and metabolism. The negative association between phthalate metabolites levels and thyroid hormones also showed in adult men [47]. A previous meta-analysis study showed the association between hypothyroidism and NAFLD [48]. However, because the mechanism whereby phthalates induced NAFLD is associated with thyroid dysfunction is unclear, further study is needed.

To our knowledge, this is the first study to report the association between urinary phthalate levels and prevalence of NAFLD in the general population. However, some limitations should be noted. First, we could not determine whether a noninvasive marker could truly indicate the prevalence of NAFLD. Liver biopsy is the most sensitive toll for clinical diagnosis of NAFLD. Nevertheless, this is not suitable for population-based studies. Among the various noninvasive tools for predicting NAFLD, we used the HSI score. The area under the receiver-operating curve of HSI was 0.812 (95\% CI $0.801-0.824)$ in the Korean population [35]. Because HSI correlated with IR [49], it could estimate the phthalates induced IR, which is a primary factor of NAFLD. However, the problem of classifying the intermediate group $(30 \leq \mathrm{HIS} \leq 36)$ as a control group was an inevitable one. Further prospective studies are required to confirm the reproducibility and accuracy of our observations. Second, this study used cross-sectional survey data; thus, it was difficult to assess the causal relationship between phthalate exposure and NAFLD. Further study is warranted to investigate the influence of phthalates on NAFLD development. Third, KoNEHS represented the drinking times in the last month and the number of glass per times instead of the amount of alcohol (g/day). Heavy drinkers who consumed alcohol more than 3 times in a week and 7-9 glasses per time in men (5-6 glasses per time in women) were defined by referring to a previous study [50]. Last but not least, the interand intra-subject variations of urinary phthalate levels were a limitation because of the relatively short half-lives. Although KoNEHS collected single spot urine samples, a sufficient number of samples may adequately reflect the average exposure level of the population to phthalate.

\section{Conclusions}

This study showed epidemiological evidence that exposure to phthalates is associated with the occurrence of NAFLD. Therefore, a reduction in phthalate exposure might help prevent NAFLD.

Author Contributions: Conceptualization, Y.-J.Y.; methodology, Y.-J.Y. and T.K.; formal analysis, Y.-J.Y. and T.K.; writing—original draft preparation, Y.-J.Y.; writing—review and editing, Y.-P.H. All authors have read and agreed to the published version of the manuscript.

Funding: This research received no external funding.

Institutional Review Board Statement: Ethical review and approval were waived for this study, due to the use of existing information/data, documents, and records.

Informed Consent Statement: Not applicable.

Data Availability Statement: This study used data from the Second Korean National Environmental Health Survey (KoNEHS) which was conducted by Ministry of Environment, National Institute of Environmental Research. The data presented in this study are available on request from the corresponding author. The data are not publicly available due to protect personal information.

Acknowledgments: This research was supported by Basic Science Research Program through the National Research Foundation of Korea (NRF) funded by the Ministry of Education (2021R1I1A3046386).

Conflicts of Interest: The authors declare no conflict of interest.

\section{References}

1. Angulo, P. Nonalcoholic fatty liver disease. N. Engl. J. Med. 2002, 346, 1221-1231. [CrossRef]

2. Loomba, R.; Sanyal, A.J. The global NAFLD epidemic. Nat. Rev. Gastroenterol. Hepatol. 2013, 10, 686-690. [CrossRef]

3. Jeong, E.H.; Jun, D.W.; Cho, Y.K.; Choe, Y.G.; Ryu, S.; Lee, S.M.; Jang, E.C. Regional prevalence of non-alcoholic fatty liver disease in Seoul and Gyeonggi-do, Korea. Clin. Mol. Hepatol. 2013, 19, 266-272. [CrossRef] [PubMed] 
4. Sarwar, R.; Pierce, N.; Koppe, S. Obesity and nonalcoholic fatty liver disease: Current perspectives. Diabetes Metab. Syndr. Obes. 2018, 11, 533-542. [CrossRef] [PubMed]

5. Williams, C.D.; Stengel, J.; Asike, M.I.; Torres, D.M.; Shaw, J.; Contreras, M.; Landt, C.L.; Harrison, S.A. Prevalence of nonalcoholic fatty liver disease and nonalcoholic steatohepatitis among a largely middle-aged population utilizing ultrasound and liver biopsy: A prospective study. Gastroenterology 2011, 140, 124-131. [CrossRef]

6. Thayer, K.A.; Heindel, J.J.; Bucher, J.R.; Gallo, M.A. Role of environmental chemicals in diabetes and obesity: A National Toxicology Program workshop review. Environ. Health Perspect. 2012, 120, 779-789. [CrossRef] [PubMed]

7. Polyzos, S.A.; Kountouras, J.; Deretzi, G.; Zavos, C.; Mantzoros, C.S. The emerging role of endocrine disruptors in pathogenesis of insulin resistance: A concept implicating nonalcoholic fatty liver disease. Curr. Mol. Med. 2012, 12, 68-82. [CrossRef]

8. Ben-Jonathan, N.; Hugo, E.R.; Brandebourg, T.D. Effects of bisphenol A on adipokine release from human adipose tissue: Implications for the metabolic syndrome. Mol. Cell. Endocrinol. 2009, 304, 49-54. [CrossRef]

9. Lim, S.; Cho, Y.M.; Park, K.S.; Lee, H.K. Persistent organic pollutants, mitochondrial dysfunction, and metabolic syndrome. Ann. N. Y. Acad. Sci. 2010, 1201, 166-176. [CrossRef]

10. Foulds, C.E.; Trevino, L.S.; York, B.; Walker, C.L. Endocrine-disrupting chemicals and fatty liver disease. Nat. Rev. Endocrinol. 2017, 13, 445-457. [CrossRef]

11. Lu, C.; Wang, Y.; Sheng, Z.; Liu, G.; Fu, Z.; Zhao, J.; Zhao, J.; Yan, X.; Zhu, B.; Peng, S. NMR-based metabonomic analysis of the hepatotoxicity induced by combined exposure to PCBs and TCDD in rats. Toxicol. Appl. Pharmacol. 2010, 248, 178-184. [CrossRef] [PubMed]

12. Wormuth, M.; Scheringer, M.; Vollenweider, M.; Hungerbuhler, K. What are the sources of exposure to eight frequently used phthalic acid esters in Europeans? Risk Anal. 2006, 26, 803-824. [CrossRef]

13. Calafat, A.M.; Ye, X.; Silva, M.J.; Kuklenyik, Z.; Needham, L.L. Human exposure assessment to environmental chemicals using biomonitoring. Int. J. Androl. 2006, 29, 166-171; discussion 181-185. [CrossRef] [PubMed]

14. Koch, H.M.; Bolt, H.M.; Preuss, R.; Angerer, J. New metabolites of di(2-ethylhexyl)phthalate (DEHP) in human urine and serum after single oral doses of deuterium-labelled DEHP. Arch. Toxicol. 2005, 79, 367-376. [CrossRef]

15. Silva, M.J.; Barr, D.B.; Reidy, J.A.; Kato, K.; Malek, N.A.; Hodge, C.C.; Hurtz, D., III; Calafat, A.M.; Needham, L.L.; Brock, J.W. Glucuronidation patterns of common urinary and serum monoester phthalate metabolites. Arch. Toxicol. 2003, 77, 561-567. [CrossRef]

16. Koch, H.M.; Bolt, H.M.; Angerer, J. Di(2-ethylhexyl)phthalate (DEHP) metabolites in human urine and serum after a single oral dose of deuterium-labelled DEHP. Arch. Toxicol. 2004, 78, 123-130. [CrossRef] [PubMed]

17. Frederiksen, H.; Skakkebaek, N.E.; Andersson, A.M. Metabolism of phthalates in humans. Mol. Nutr. Food Res. 2007, 51, 899-911. [CrossRef] [PubMed]

18. Culty, M.; Thuillier, R.; Li, W.; Wang, Y.; Martinez-Arguelles, D.B.; Benjamin, C.G.; Triantafilou, K.M.; Zirkin, B.R.; Papadopoulos, $\mathrm{V}$. In utero exposure to di-(2-ethylhexyl) phthalate exerts both short-term and long-lasting suppressive effects on testosterone production in the rat. Biol. Reprod. 2008, 78, 1018-1028. [CrossRef]

19. Parks, L.G.; Ostby, J.S.; Lambright, C.R.; Abbott, B.D.; Klinefelter, G.R.; Barlow, N.J.; Gray, L.E., Jr. The plasticizer diethylhexyl phthalate induces malformations by decreasing fetal testosterone synthesis during sexual differentiation in the male rat. Toxicol. Sci. 2000, 58, 339-349. [CrossRef]

20. Hatch, E.E.; Nelson, J.W.; Qureshi, M.M.; Weinberg, J.; Moore, L.L.; Singer, M.; Webster, T.F. Association of urinary phthalate metabolite concentrations with body mass index and waist circumference: A cross-sectional study of NHANES data, 1999-2002. Environ. Health 2008, 7, 27. [CrossRef]

21. Buser, M.C.; Murray, H.E.; Scinicariello, F. Age and sex differences in childhood and adulthood obesity association with phthalates: Analyses of NHANES 2007-2010. Int. J. Hyg. Environ. Health 2014, 217, 687-694. [CrossRef]

22. Gayathri, N.S.; Dhanya, C.R.; Indu, A.R.; Kurup, P.A. Changes in some hormones by low doses of di (2-ethyl hexyl) phthalate (DEHP), a commonly used plasticizer in PVC blood storage bags \& medical tubing. Indian J. Med. Res. 2004, 119, 139-144. [PubMed]

23. Stahlhut, R.W.; van Wijngaarden, E.; Dye, T.D.; Cook, S.; Swan, S.H. Concentrations of urinary phthalate metabolites are associated with increased waist circumference and insulin resistance in adult U.S. males. Environ. Health Perspect. 2007, 115, 876-882. [CrossRef]

24. Gollamudi, R.; Prasanna, H.R.; Rao, R.H.; Lawrence, W.H.; Autian, J. Impaired metabolism of di(2-ethylhexyl) phthalate (DEHP) in old rats-An in vitro study. J. Toxicol. Environ. Health 1983, 12, 623-632. [CrossRef] [PubMed]

25. Yang, Y.J.; Park, M.S.; Lee, E.J.; Hong, Y.P. The Development of Metabolic Derangement in Male Offspring after Perinatal Exposure to Di-(2-Ethylhexyl) Phthalate. Biomed. Environ. Sci. 2018, 31, 531-534. [CrossRef]

26. Hao, C.; Cheng, X.; Xia, H.; Ma, X. The endocrine disruptor mono-(2-ethylhexyl) phthalate promotes adipocyte differentiation and induces obesity in mice. Biosci. Rep. 2012, 32, 619-629. [CrossRef]

27. Knight, B.L.; Hebbachi, A.; Hauton, D.; Brown, A.M.; Wiggins, D.; Patel, D.D.; Gibbons, G.F. A role for PPARalpha in the control of SREBP activity and lipid synthesis in the liver. Biochem. J. 2005, 389, 413-421. [CrossRef] [PubMed]

28. Chen, H.; Zhang, W.; Rui, B.B.; Yang, S.M.; Xu, W.P.; Wei, W. Di(2-ethylhexyl) phthalate exacerbates non-alcoholic fatty liver in rats and its potential mechanisms. Environ. Toxicol. Pharmacol. 2016, 42, 38-44. [CrossRef] 
29. Zhang, W.; Shen, X.Y.; Zhang, W.W.; Chen, H.; Xu, W.P.; Wei, W. The effects of di 2-ethyl hexyl phthalate (DEHP) on cellular lipid accumulation in HepG2 cells and its potential mechanisms in the molecular level. Toxicol. Mech. Methods 2017, 27, 245-252. [CrossRef]

30. Huff, M.; da Silveira, W.A.; Carnevali, O.; Renaud, L.; Hardiman, G. Systems Analysis of the Liver Transcriptome in Adult Male Zebrafish Exposed to the Plasticizer (2-Ethylhexyl) Phthalate (DEHP). Sci. Rep. 2018, 8, 2118. [CrossRef] [PubMed]

31. Feige, J.N.; Gerber, A.; Casals-Casas, C.; Yang, Q.; Winkler, C.; Bedu, E.; Bueno, M.; Gelman, L.; Auwerx, J.; Gonzalez, F.J.; et al. The pollutant diethylhexyl phthalate regulates hepatic energy metabolism via species-specific PPARalpha-dependent mechanisms. Environ. Health Perspect. 2010, 118, 234-241. [CrossRef]

32. Bai, J.; He, Z.; Li, Y.; Jiang, X.; Yu, H.; Tan, Q. Mono-2-ethylhexyl phthalate induces the expression of genes involved in fatty acid synthesis in HepG2 cells. Environ. Toxicol. Pharmacol. 2019, 69, 104-111. [CrossRef]

33. Zhang, Y.; Ge, S.; Yang, Z.; Li, Z.; Gong, X.; Zhang, Q.; Dong, W.; Dong, C. Disturbance of di-(2-ethylhexyl) phthalate in hepatic lipid metabolism in rats fed with high fat diet. Food Chem. Toxicol. 2020, 146, 111848. [CrossRef]

34. An, S.; Lee, E.; Jeong, S.-H.; Hong, Y.-p.; Ahn, S.; Yang, Y.-J. Perinatal exposure to di-(2-ethylhexyl) phthalate induces hepatic lipid accumulation mediated by diacylglycerol acyltransferase 1. Hum. Exp. Toxicol. 2021, 09603271211003314. [CrossRef] [PubMed]

35. Lee, J.H.; Kim, D.; Kim, H.J.; Lee, C.H.; Yang, J.I.; Kim, W.; Kim, Y.J.; Yoon, J.H.; Cho, S.H.; Sung, M.W.; et al. Hepatic steatosis index: A simple screening tool reflecting nonalcoholic fatty liver disease. Dig. Liver Dis. 2010, 42, 503-508. [CrossRef] [PubMed]

36. Chang, J.W.; Lee, H.W.; Kim, B.K.; Park, J.Y.; Kim, D.Y.; Ahn, S.H.; Han, K.H.; Kim, S.U. Hepatic Steatosis Index in the Detection of Fatty Liver in Patients with Chronic Hepatitis B Receiving Antiviral Therapy. Gut Liver 2020. [CrossRef]

37. Kim, D.; Yoo, E.R.; Li, A.A.; Cholankeril, G.; Tighe, S.P.; Kim, W.; Harrison, S.A.; Ahmed, A. Elevated urinary bisphenol A levels are associated with non-alcoholic fatty liver disease among adults in the United States. Liver Int. 2019, 39, 1335-1342. [CrossRef] [PubMed]

38. Jia, Y.; Liu, T.; Zhou, L.; Zhu, J.; Wu, J.; Sun, D.; Xu, J.; Wang, Q.; Chen, H.; Xu, F.; et al. Effects of Di-(2-ethylhexyl) Phthalate on Lipid Metabolism by the JAK/STAT Pathway in Rats. Int. J. Environ. Res. Public Health 2016, 13, 1085. [CrossRef]

39. Lv, Z.; Cheng, J.; Huang, S.; Zhang, Y.; Wu, S.; Qiu, Y.; Geng, Y.; Zhang, Q.; Huang, G.; Ma, Q.; et al. DEHP induces obesity and hypothyroidism through both central and peripheral pathways in C3H/He mice. Obesity 2016, 24, 368-378. [CrossRef]

40. Das, K.; Das, K.; Mukherjee, P.S.; Ghosh, A.; Ghosh, S.; Mridha, A.R.; Dhibar, T.; Bhattacharya, B.; Bhattacharya, D.; Manna, B.; et al. Nonobese population in a developing country has a high prevalence of nonalcoholic fatty liver and significant liver disease. Hepatology 2010, 51, 1593-1602. [CrossRef]

41. Cho, H.C. Prevalence and Factors Associated with Nonalcoholic Fatty Liver Disease in a Nonobese Korean Population. Gut Liver 2016, 10, 117-125. [CrossRef]

42. Feldman, A.; Eder, S.K.; Felder, T.K.; Kedenko, L.; Paulweber, B.; Stadlmayr, A.; Huber-Schonauer, U.; Niederseer, D.; Stickel, F.; Auer, S.; et al. Clinical and Metabolic Characterization of Lean Caucasian Subjects With Non-alcoholic Fatty Liver. Am. J. Gastroenterol. 2017, 112, 102-110. [CrossRef]

43. Kim, S.H.; On, J.W.; Pyo, H.; Ko, K.S.; Won, J.C.; Yang, J.; Park, M.J. Percentage fractions of urinary di(2-ethylhexyl) phthalate metabolites: Association with obesity and insulin resistance in Korean girls. PLoS ONE 2018, 13, e0208081. [CrossRef]

44. Rengarajan, S.; Parthasarathy, C.; Anitha, M.; Balasubramanian, K. Diethylhexyl phthalate impairs insulin binding and glucose oxidation in Chang liver cells. Toxicol. Vitro 2007, 21, 99-102. [CrossRef]

45. Sinha, R.A.; Singh, B.K.; Yen, P.M. Direct effects of thyroid hormones on hepatic lipid metabolism. Nat. Rev. Endocrinol. 2018, 14, 259-269. [CrossRef] [PubMed]

46. Liu, C.; Zhao, L.; Wei, L.; Li, L. DEHP reduces thyroid hormones via interacting with hormone synthesis-related proteins, deiodinases, transthyretin, receptors, and hepatic enzymes in rats. Environ. Sci. Pollut. Res. Int. 2015, 22, 12711-12719. [CrossRef] [PubMed]

47. Meeker, J.D.; Calafat, A.M.; Hauser, R. Di(2-ethylhexyl) phthalate metabolites may alter thyroid hormone levels in men. Environ. Health Perspect. 2007, 115, 1029-1034. [CrossRef]

48. Mantovani, A.; Nascimbeni, F.; Lonardo, A.; Zoppini, G.; Bonora, E.; Mantzoros, C.S.; Targher, G. Association Between Primary Hypothyroidism and Nonalcoholic Fatty Liver Disease: A Systematic Review and Meta-Analysis. Thyroid 2018, 28, 1270-1284. [CrossRef] [PubMed]

49. Fedchuk, L.; Nascimbeni, F.; Pais, R.; Charlotte, F.; Housset, C.; Ratziu, V.; Group, L.S. Performance and limitations of steatosis biomarkers in patients with nonalcoholic fatty liver disease. Aliment. Pharmacol. Ther. 2014, 40, 1209-1222. [CrossRef]

50. Kang, Y.; Park, J.; Youn, K. Association between urinary phthalate metabolites and obesity in adult Korean population: Korean National Environmental Health Survey (KoNEHS), 2012-2014. Ann. Occup Environ. Med. 2019, 31, e23. [CrossRef] 